\title{
Hidrogeoquímica de cursos de água: influência da ocupação humana sobre parâ- metros físico-químicos no Município de Porto Alegre, RS
}

\author{
Rafael MIDUGNOํㅜ \& Ari ROISENBERG ${ }^{2}$
}

Instituto de Geociências, Universidade Federal do Rio Grande do Sul. Av. Bento Gonçalves, 9500, CEP 91.501-970, Porto Alegre, RS, Brasil. Emails: rafaelm@fepam.rs.gov.br, ari.roisenberg@ufrgs.br.

Recebido em 07/2011. Aceito para publicação em 12/2012.

Versão online publicada em 06/09/2013 (www.pesquisasemgeociencias.ufrgs.br)

\begin{abstract}
Resumo - Neste trabalho são apresentados resultados de avaliação de impacto ambiental em três sub-bacias hidrográficas, situadas em diferentes contextos urbano-paisagísticos, na cidade de Porto Alegre/RS. A influência de atividades humanas sobre a composição química de águas e sedimentos, coletados sazonalmente, foi determinada a partir da análise em laboratório de parâmetros físico-químicos, tais como $\mathrm{Fe}, \mathrm{Mn}, \mathrm{Al}, \mathrm{Cu}$, $\mathrm{Zn}, \mathrm{Cr}, \mathrm{Cd}, \mathrm{Pb}, \mathrm{Hg}, \mathrm{DBO}_{5}$, DQO e matéria orgânica, além de parâmetros in situ como potencial hidrogeniônico- $\mathrm{pH}$, temperatura-T, potencial de redução-Eh, condutividade elétrica-CE e oxigênio dissolvido-OD, de modo a estabelecer distinção entre dejetos gerados em cada cenário. Os resultados revelam que os contextos urbano-paisagísticos influenciam sensivelmente a composição química dos cursos d'água. Por outro lado, a sazonalidade parece exercer papel secundário, considerando que não houve variação signiticativa na concentração de poluentes no período de superávit hídrico, compreendido entre Abril e Outubro. Desse modo, constatamos que os graus de poluição seguem a sequência lógica dos padrões de urbanização: Periurbana é a zona em que a produção de dejetos é menor, a zona Urbana Mista é aquela onde há adensamento populacional e presença de indústrias e outras atividades potencialmente poluidoras, e Urbana Rarefeita é a zona que apresenta características intermediárias. Ao mesmo tempo, verifica-se que, em ambos os cenários, o ambiente fluvial está exposto a processos contínuos de degradação,considerando que dejetos são lançados diretamente na água, fato que contribui para o aumento dos gastos com seu tratamento.

Palavra-chave: hidrogeoquímica, ambiente urbano, avaliação da qualidade da água, efluente, esgoto, poluição antropogênica.
\end{abstract}

Abstract - HYDROGEOCHEMISTRY OF WATER COURSES: THE INFLUENCE OF HUMAN OCCUPATION ON PHYSICOCHEMiCAL PARAMETERS IN THE CITY OF PORTO ALEGRE, SOUTHERN BRAZIL. This paper presents the results of environmental impact study in three hydrographic sub-basins located in different urban-landscape contexts in the city of Porto Alegre, State of Rio Grande do Sul. The influence of human activities on chemical composition of water and sediments sampled seasonally was determined from the analysis in laboratory of physicochemical parameters such as $\mathrm{Fe}, \mathrm{Mn}, \mathrm{Al}, \mathrm{Cu}, \mathrm{Zn}, \mathrm{Cr}, \mathrm{Cd}, \mathrm{Pb}, \mathrm{Hg}, \mathrm{BOD}_{5}, \mathrm{COD}$ and organic matter, as well in situ determinations such as potential of hydrogen- $\mathrm{pH}$, temperature-T, reduction potential-Eh, electrical conductivity-EC and dissolved oxigen-DO, in order to establish the distinction between wastewater charges generated in each scenario. The results show that urban-landscape contexts influence substantially the chemical composition of water courses. Moreover, seasonality displays a secondary role, whereas there was no significant variation in pollutant concentrations during the water surplus period, between April and October. Thus, it appears that the degree of pollution follows the logical sequence of patterns of urbanization in Brazil: Suburban is the zone where the production of wastewater is the smallest; the mixed urban zone is one with high population density, presence of industries and other potentially polluting activities; and the sparse urban zone that presents intermediate characteristics. At the same time, it appears that, in both scenarios, the riverine environment is exposed to continuous processes of degradation, since wastewater charges are released directly on it, fact that contribute with the raise of the financial costs of water treatment.

Keywords: hydrogeochemistry, urban environment, water quality evaluation, wastewater, sewage, anthropogenic pollution.

\section{Introdução}

Cidades representam sistemas abertos (Bertalanffy, 1973), compostos por entradas e saídas de massa e energia sob a forma de fluxos concentrados. Em áreas urbanas, as obras de saneamento básico fornecem a infra-estrutura essencial à ocupação ordenada do ter- ritório. Ao mesmo tempo, a pavimentação de vias e as construções reduzem a área de infiltração superficial, causando mudanças no regime de escoamento superficial. Como decorrência, o lançamento de efluentes é concentrado em pontos específicos da rede de drenagem. Quando o volume de resíduos orgânicos (esgoto doméstico) e inorgânicos (efluentes industriais) su- 
pera a capacidade de autodepuração do meio aquático, o ecossistema local entra em desequilíbrio, o que traz reflexos negativos para as condições sanitárias e, consequentemente, para a saúde da população. Desta forma, pode-se afirmar que a ocupação intensiva do território, especialmente em locais com rede de saneamento básico precária, é um dos fatores que mais contribui para a degradação ambiental, juntamente com atividades industriais e agrícolas de elevado grau poluidor.

Políticas e programas visando a gestão territorial vêm elegendo as bacias hidrográficas como unidades básicas fundamentais. Esta escolha leva em consideração a capacidade que as bacias hidrográficas e seus elementos formadores (rios, afluentes e subafluentes) possuem de refletir propriedades das áreas drenadas. A bacia hidrográfica, sendo um recorte de uma porção da superfície cartograficamente delimitável, se assemelha a outras unidades de gestão do território, notadamente os geossistemas de Bertrand (1971), Sotchava (1977) e Christofoletti (1999) e as unidades ambientais ecodinâmicas de Tricart (1977) e Ross (1990), focados nos processos morfogenéticos e pedogenéticos. No entanto, o conceito de bacia hidrográfica é mais objetivo e se ajusta melhor ao tipo e escala dos elementos urbanos. Já os geossistemas e a ecodinâmica baseiam-se fundamentalmente em processos naturais.

A região de Porto Alegre é marcada pela junção de sete ecorregiões (Menegat et al., 1998). Soma-se a este contexto de ecodiversidade o arranjo heterogêneo entre unidades de paisagem natural e polígonos de ação antrópica (Crepani et al., 1996). Para o presente estudo, foram analisadas três sub-bacias hidrográficas, representativas do conjunto de macrozonas definidas pelo Plano Diretor de Desenvolvimento Urbano Ambiental - PDDUA de Porto Alegre (1999).

Do ponto de vista sanitário, os arroios são vias através das quais a maior parte dos dejetos do município atinge, direta ou indiretamente, o Lago Guaíba, a principal fonte de captação de água para abastecimento público da cidade.

O presente trabalho tem como objetivo principal determinar a influência do contexto urbano-ambiental sobre a evolução composicional das águas e sedimentos nas sub-bacias hidrográficas, verificando se cada contexto gera dejetos composicionalmente distintos entre si e, consequentemente, cargas poluentes heterogêneas. Em segundo plano, avaliar a variação sazonal de parâmetros físico-químicos e identificar trechos dos cursos d'água nos quais os limites de qualidade, estabelecidos pela legislação para estes parâmetros conforme os usos preponderantes, são ultrapassados. Finalmente, caracterizar as cargas poluentes que atingem o Lago Guaíba, como forma de verificar o quanto a degradação dos arroios afeta sua composição química.

\section{2 Áreas de estudo}

Situadas no município de Porto Alegre, capital do Estado do Rio Grande do Sul, Região Sul do Brasil, as áreas de estudos representam sub-bacias hidrográficas com características urbano-ambientais distintas. A localização do município em relação aos limites estadual e federal é apresentada a seguir (Fig. 1).

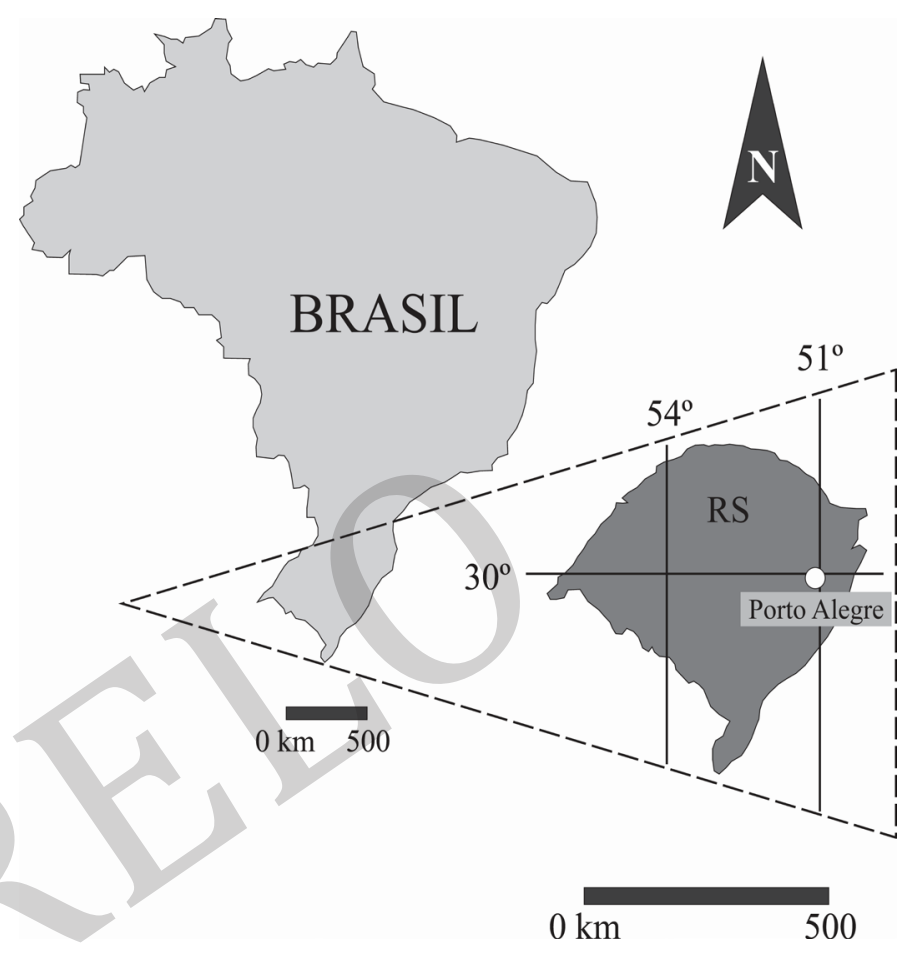

Figura 1. Mapa de localização do Município de Porto Alegre.

O clima é classificado como subtropical úmido com temperatura média do ar de $19,4^{\circ} \mathrm{C}$, valor máximo médio de $29,9^{\circ} \mathrm{C}$, mínimo médio de $15,2^{\circ} \mathrm{C}$ e amplitude térmica máxima de $36,7^{\circ} \mathrm{C}$. A região de Porto Alegre caracteriza-se por chuvas distribuídas regularmente ao longo do ano. No entanto, o extrato do balanço hídrico comprova que a intensidade de chuvas é maior no período compreendido entre os meses de Maio e Outubro (Sentelhas et al., 1999). A precipitação pluviométrica anual média é de $1.324 \mathrm{~mm}$, a umidade relativa do ar média é de 75,9 \%, a insolação anual média é de 2.310 $\mathrm{h}$ e o vento predominante é Sudeste de baixa velocidade (1,35 e 2,8 m/s), conforme Menegat et al. (1998), Guerra et al. (1998), Lange \& Guerra (2002) e Freitas (1998). Segundo a Classificação Climática de KöppenGeiger, a área está inserida no subtipo climático "Cfa", que representa áreas de clima temperado úmido com Verão quente (Peel et al., 2007).

A geologia regional é representada pelo Batólito Pelotas, um complexo granítico situado na porção leste do Escudo Sul-rio-grandense, com extensão em torno de $2.500 \mathrm{~km}^{2}$, caráter multi-intrusivo e polifásico, relacionado com o Ciclo Orogenético Brasiliano (FragosoCesar, 1986). Localizadamente, verifica-se a presença de dois domínios (Fig. 2), (i) o Embasamento Cristalino pré-Cambriano, representado pela associação de 
rochas graníticas e gnáissicas, e (ii) a Cobertura Sedimentar Cenozóica, representada, predominantemente, por depósitos aluviais, fluvio-lacustrinos e lagunares (Fig. 2). Como resultado, registra-se a constituição de três assembléias distintas de materiais (Menegat et al., 1998): (i) ao Norte, terrenos recobertos por sedimentos fluviais do Rio Gravataí e ilhas do Delta do Jacuí; (ii) ao centro, altos topográficos representados por cristas e colinas graníticas e; (iii) ao Sul, morros graníticos isolados circundados por sedimentos lacustres. A distribuição desses materiais nas áreas de estudo pode ser identificada na figura 2 , a seguir:

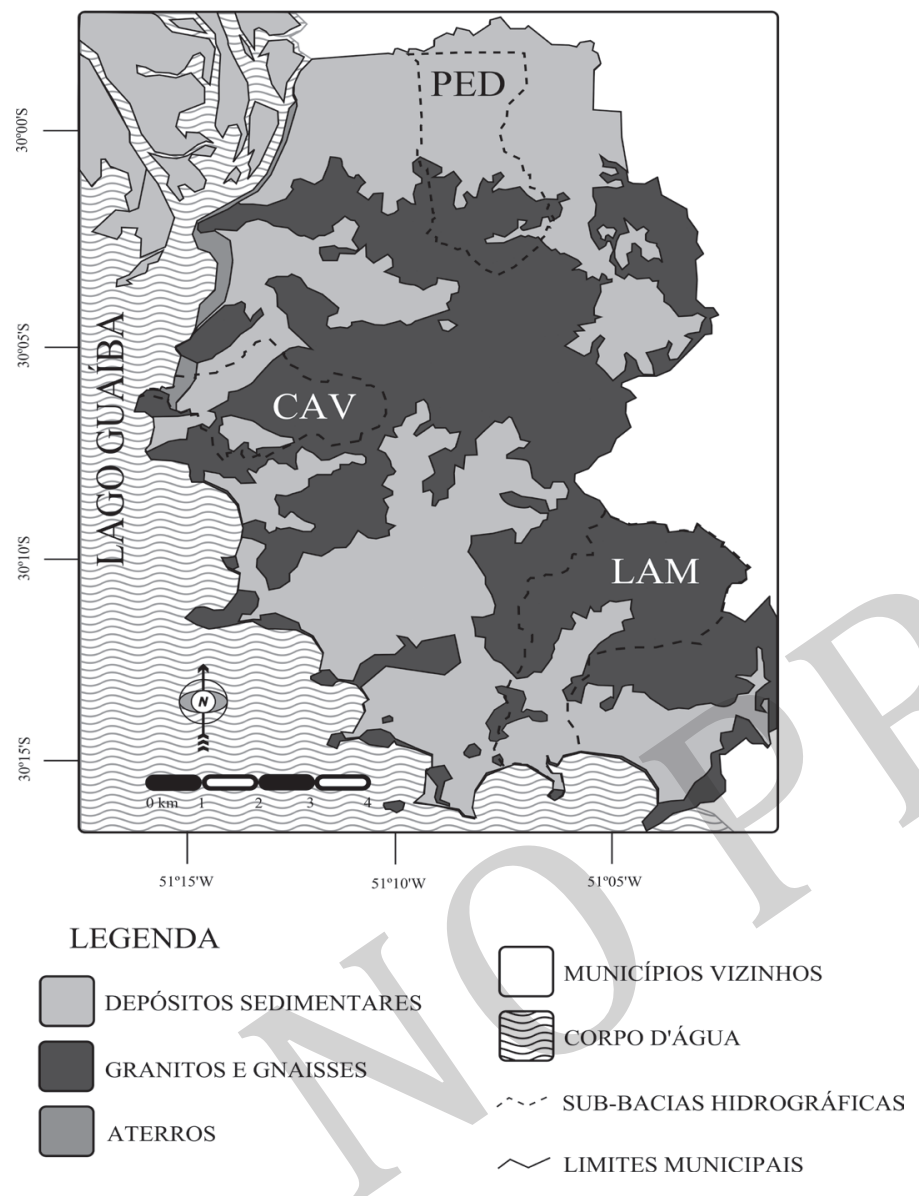

Figura 2. Geologia simplificada do Município de Porto Alegre e sua ocorrência nas sub-bacias dos arroios Lami (LAM), Cavalhada (CAV) e Passo das Pedras (PED).

A cobertura de solos do município é formada por solos litólicos e podzólicos vermelho-amarelos, resultantes da pedogênese das rochas granitóides, e solos hidromórficos (planossolos, glei e aluvionares), desenvolvidos sobre sedimentos de origem lagunar e flúvio-lacustre (IBGE, 1986). Ocorrem ainda depósitos tecnogênicos (aterros) construídos ao longo de faixas marginais ao Lago Guaíba, situadas na zona central e norte do município, onde a urbanização é intensa.

A rede hidrográfica é constituída por vinte e sete sub-bacias, inseridas na Bacia Hidrográfica do Guaíba, na Região Hidrográfica do Guaíba (Guerra et al., 1998). Os canais principais de escoamento em cada bacia compartilham a mesma área de nascente, situada na porção Leste do município. A distribuição espacial des- sas vertentes resulta em padrão radial de escoamento das águas, com drenagem apresentando padrão dendrítico a subdendrítico no trecho superior e em parte do médio, em resposta ao condicionamento geoestrutural imposto por falhas e fraturas desenvolvidas sobre o embasamento granítico (Menegat et al., 1998). Nas zonas de topografia suave, a drenagem desenvolve padrão subparalelo a paralelo (e.g. canal único de escoamento).

\subsection{Classificação e índices relacionados ao espaço urba- no e a ocupação humana}

A densidade populacional é um dos principais fatores utilizados para classificar sub-bacias hidrográficas em diferentes classes. Nesse contexto, as sub-bacias selecionadas para o presente estudo enquadram-se nas seguintes faixas de valor, de acordo com dados do IBGE (2010) e com o PDDUA (Porto Alegre, 1999):

- até $500 \mathrm{hab} / \mathrm{km}^{2}$ (Arroio Lami);

- de 1.001 à 5.000 hab $/ \mathrm{km}^{2}$ (Arroio Cavalhada); e

- acima de 5.000 hab $/ \mathrm{km}^{2}$ (Arroio Passo das Pedras).

No presente trabalho, a partir dos dados demográficos do IBGE, buscou-se testar a hipótese de que o volume de resíduos sólidos e líquidos gerados em cada um desses contextos tende a refletir o seu número de habitantes (IBGE, 2010). Nos locais onde não há rede de coleta e pré-tratamento de dejetos, são registrados níveis elevados de degradação dos recursos hídricos (Porto Alegre, 1999).

Dentre as sub-bacias estudadas, a do Arroio Lami ( $99 \mathrm{hab} / \mathrm{km}^{2}$ ) é a que apresenta o menor grau de urbanização, em virtude da ampla predominância de cobertura vegetal e baixa densidade populacional, como pode ser verificado na figura 3. Essa constatação é reforçada pela presença insignificante de áreas impermeabilizadas.

Dentre as sub-bacias que possuem grau de urbanização elevado, a do Arroio Cavalhada conta com 4.476 $\mathrm{hab} / \mathrm{km}^{2}$, valor muito semelhante ao registrado pela do Arroio Passo das Pedras (5.081 hab $/ \mathrm{km}^{2}$ ). Esta condição é reflexo do padrão de ocupação rarefeita verificado nas porções mais elevadas daquela sub-bacia.

Segundo o zoneamento urbano municipal (Porto Alegre, 1999), a bacia do Arroio Passo das Pedras está inserida no principal eixo de expansão da cidade, que se estende a Leste do Centro Histórico. Já a bacia do Arroio Cavalhada tem suas cabeceiras situadas em macrozona onde se desenvolvem, concomitantemente, atividades típicas dos meios rurais e urbanos, gradando a jusante para zonas de expansão secundária da cidade, que não seguem o padrão de desenvolvimento urbano da área central. A sub-bacia do Arroio Lami, por sua vez, caracteriza-se pelo amplo domínio do ambiente rural. No entanto, dada a proximidade com aglomerados urbanos, não se encontra isolada de influência da circulação humana. 
Do ponto de vista industrial, verificam-se algumas diferenças entre as sub-bacias estudadas. Na sub-bacia do Arroio Cavalhada, estão instaladas indústrias dos setores alimentícios (três unidades) e químicos (uma unidade), além de uma do setor metalúrgico (uma unidade). Na sub-bacia do Arroio Passo das Pedras, verifica-se a presença de indústrias dos setores químicos (uma unidade) e metalúrgicos (quatro unidades) e, secundariamente, do setor de alimentos (uma unidade). A sub-bacia do Arroio Lami, por sua vez, apresenta apenas uma concentração de pequenos produtores rurais, sem registro de indústrias importantes na sua área de abrangência.

\subsection{Materiais e métodos}

Trabalhos preliminares foram desenvolvidos com a finalidade de obter informações que auxiliassem na caracterização das sub-bacias hidrográficas que formam a rede hidrográfica municipal, permitindo-nos identificar sub-bacias representativas de cada contexto urbano-ambiental. Os dados obtidos nesta etapa forneceram informações sobre a densidade populacional, uso e ocupação do solo, características físicas dos cursos d'água, bem como da geologia, pedologia e cobertura vegetal.

A análise de dados de balanço hídrico permitiu a definição dos períodos mais favoráveis para a realização das campanhas de amostragem. A primeira campanha ocorreu em Setembro de 2006, mês com precipitação média de $140 \mathrm{~mm}$ e que marca o fim do período de superávit hídrico, e a segunda em Abril de 2008, mês com precipitação média de $86 \mathrm{~mm}$ e correspondente ao término do período de déficit hídrico (Porto Alegre, 2012).

A densidade de pontos da rede de amostragem foi estabelecida com base na variação produzida pelas variáveis naturais e antrópicas. De acordo com os perfis longitudinais dos arroios, foram selecionados um ponto no curso superior, dois pontos no curso médio e dois pontos no curso inferior (Fig. 3), totalizando sessenta amostras de águas e sedimentos nos pontos de maior fluxo hídrico.

Para a armazenagem da água, foram utilizados frascos de polietileno de 250 e $500 \mathrm{~mL}$ e frascos de vidro âmbar de $500 \mathrm{~mL}$, mantidos refrigerados em caixas isotérmicas (CETESB, 1987) por um período de até $8 \mathrm{~h}$ até o encaminhamento para o laboratório. Os frascos para análise de metais foram previamente acidificados, no intuito de preservar a estabilidade química desses elementos. Cinco parâmetros (potencial hidrogeniônico-pH, temperatura-T, potencial de redução-Eh, condutividade elétrica-CE e oxigênio dissolvido-OD) foram determinados in situ com o auxílio de multiparâmetro Hach (sensION 156) e sonda multiparamétrica Horiba. Já os sedimentos de corrente foram coletados com amostrador tipo mudsnapper e acondicionados em sacos plásticos.

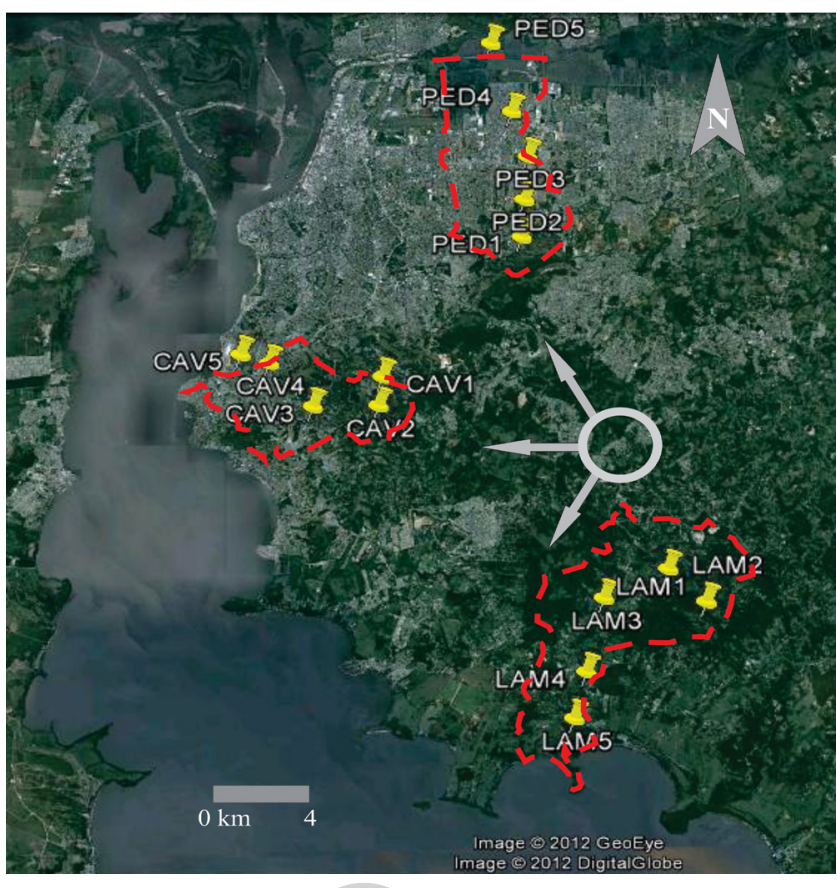

Figura 3. Localização geográfica das sub-bacias hidrográficas e dos pontos de coleta no município de Porto Alegre. Obs: círculo = área de nascentes; setas = direções de escoamento do fluxo de água.

Com o intuito de avaliar o impacto antropogênico, foram analisados sessenta elementos e compostos químicos, com o uso de cromatógrafo iônico e de espectrofotômetro de absorção atômica simples ou acoplado a forno de grafite e gerador de hidretos. As análises foram realizadas de acordo com metodologias do Standard Methods for the Examination of Water and Wastewater (APHA, 1999) e da United States Environmental Protection Agency (USEPA, 1979). Além dessas análises, foram determinados os parâmetros Demanda Bioquímica de Oxigênio $\left(\mathrm{DBO}_{5}\right.$ ) e Demanda Química de Oxigênio (DQO) na água e conteúdo de matéria orgânica (MO) nos sedimentos.

\section{Resultados}

\subsection{Análises de águas superficiais}

As tabelas 1, 2 e 3 sumarizam os resultados de parâmetros físico-químicos e concentrações de metais dissolvidos nas águas. Dos cinquenta e dois elementos analisados por espectrometria, somente nove metais ( $\mathrm{Fe}, \mathrm{Mn}, \mathrm{Al}, \mathrm{Cu}, \mathrm{Zn}, \mathrm{Cr}, \mathrm{Cd}, \mathrm{Pb}$ e $\mathrm{Hg}$ ) apresentaram concentrações acima do limite de detecção (LD) do método analítico. Os parâmetros cloreto, fosfato, nitrato, sulfato, cálcio, magnésio, potássio e sódio registraram valores inferiores aos limites estabelecidos pela Resolução 357/2005 do Conselho Nacional de Meio Ambiente - CONAMA e, por esta razão, eles não constam nas tabelas a seguir.

Pode-se verificar que os valores de $\mathrm{DBO}_{5}$ encontram-se acima do limite de estabelecido pelo CONAMA para águas doce Classe 2 em vinte e sete das trinta amostras analisadas nas três sub-bacias e nas duas campanhas de amostragem, apontando uma variação 
Tabela 1. Parâmetros físico-químicos e concentrações de metais $\left(\mathrm{mg} \mathrm{L}^{-1}\right)$ na água da sub-bacia do Arroio Lami. Obs: em negrito, valores acima do limite estabelecido pela resolução CONAMA no 357/ 2005 para águas doce Classe 2. S = período de déficit hídrico (seco); C = período de superávit hídrico (chuvoso).

\begin{tabular}{l|c|c|c|c|c|c|c|c|c|c|c}
\hline Parâmetro & LAM 1C & LAM 1S & LAM 2C & LAM 2S & LAM 3C & LAM 3S & LAM 4C & LAM 4S & LAM 5C & LAM 5S & CONAMA \\
\hline $\mathbf{p H}$ & 6.3 & 5,9 & 6,2 & 6,3 & 6,8 & 6,9 & 6,6 & 6,8 & 6,4 & 6,8 \\
T & 22 & 19 & 28 & 17 & 24 & 16 & 19 & 17 & 21 & 19 & - \\
CE & 110 & 84 & 95 & 53 & 129 & 80 & 132 & 96 & 176 & 84 & - \\
OD & 5,5 & 11,8 & 6,3 & 9,1 & 7,3 & 9,6 & 7,3 & 10 & 6 & 7,1 & - \\
DBO & $\mathbf{9 , 4}$ & $\mathbf{7 , 0}$ & $\mathbf{7 , 1}$ & $\mathbf{7 , 0}$ & $\mathbf{7 , 5}$ & $\mathbf{8 , 0}$ & $\mathbf{7 , 4}$ & $\mathbf{8 , 0}$ & $\mathbf{9 , 9}$ & $\mathbf{6 , 0}$ & 5 \\
DQO & 30,0 & 16,0 & 22,8 & 12,0 & 24,2 & 16,0 & 23,7 & 12,0 & 31,8 & 16,0 & - \\
Fe & $\mathbf{0 , 4 2}$ & $\mathbf{2 , 3 2}$ & $\mathbf{1 , 3 2}$ & $\mathbf{0 , 9 2}$ & $\mathbf{2 , 2 9}$ & $\mathbf{1 , 6 7}$ & $\mathbf{1 , 6 7}$ & $\mathbf{0 , 9 3}$ & $\mathbf{1 , 5 3}$ & $\mathbf{1 , 8 8}$ & 0,3 \\
Mn & $<0,001$ & $<0,001$ & 0,06 & $<0,001$ & $\mathbf{0 , 1 1}$ & 0,01 & 0,06 & 0,03 & 0,09 & $<0,001$ & 0,1 \\
Al & $\mathbf{0 , 3 3}$ & $<0,007$ & $\mathbf{2 , 0 0}$ & $\mathbf{1 , 2 6}$ & $\mathbf{1 , 3 6}$ & $\mathbf{1 , 8 1}$ & $\mathbf{1 , 4 3}$ & $\mathbf{1 , 4 5}$ & $\mathbf{0 , 6 5}$ & $\mathbf{2 , 8 8}$ & 0,1 \\
Cu & $<0,002$ & $<0,002$ & $<0,002$ & $<0,002$ & $<0,002$ & $<0,002$ & $\mathbf{0 , 1 4}$ & $<0,002$ & $<0,002$ & $<0,002$ & 0,009 \\
Zn & 0,02 & $<0,003$ & 0,03 & $<0,003$ & 0,02 & $<0,003$ & 0,03 & $<0,003$ & 0,10 & $<0,003$ & 0,18 \\
Cr & $<0,002$ & $<0,002$ & $<0,002$ & $<0,002$ & $<0,002$ & $<0,002$ & $<0,002$ & $<0,002$ & $<0,002$ & $<0,002$ & 0,05 \\
Cd & $\mathbf{0 , 0 0 2}$ & $<0,002$ & $<0,002$ & $<0,002$ & $<0,002$ & $<0,002$ & $<0,002$ & $<0,002$ & $<0,002$ & $<0,002$ & 0,001 \\
Pb & $\mathbf{0 , 0 5}$ & $<0,003$ & $<0,003$ & $<0,003$ & $<0,003$ & $<0,003$ & $<0,003$ & $<0,003$ & $<0,003$ & $<0,003$ & 0,01 \\
Hg & $<0,00002$ & $<0,00002$ & $<0,00002$ & $<0,00002$ & $<0,00002$ & $<0,00002$ & $<0,00002$ & $<0,00002$ & $<0,00002$ & $<0,00002$ & 0,0002 \\
\hline
\end{tabular}

Tabela 2. Parâmetros físico-químicos e concentrações de metais ( $\mathrm{mg} \mathrm{L}^{-1}$ ) na água da sub-bacia do Arroio Cavalhada Obs: em negrito, valores acima do limite estabelecido pela resolução CONAMA no 357/ 2005 para águas doce Classe 2. S = período de déficit hídrico (seco); C = período de superávit hídrico (chuvoso).

\begin{tabular}{|c|c|c|c|c|c|c|c|c|c|c|c|}
\hline Parâmetro & CAV 1C & CAV 1S & CAV 2C & CAV 2S & CAV 3C & CAV 3S & CAV 4C & CAV 4S & CAV 5C & CAV 5S & CONAMA \\
\hline $\mathrm{pH}$ & 5,3 & 7,3 & 5,9 & 7,1 & 5,7 & 7 & 7,2 & 6,7 & 7,2 & 6,4 & - \\
\hline $\mathrm{T}$ & 16 & 20 & 19 & 18 & 21 & 16 & 32 & 16 & 24 & 17 & - \\
\hline CE & 59 & 41 & 191 & 182 & 256 & 258 & 642 & 404 & 664 & 507 & - \\
\hline OD & 7,9 & 3,2 & 7 & 4,6 & 6,3 & 8,2 & 2 & 7,8 & 1,8 & 7,7 & - \\
\hline $\mathrm{DBO}_{5}$ & 6,9 & 4,0 & 7,4 & 7,0 & 7,1 & 3,0 & 7,0 & 11,0 & 7,7 & 36,0 & 5 \\
\hline DQO & 20,8 & 8,0 & 22,4 & 12,0 & 21,6 & 8,0 & 21,2 & 20,0 & 24,0 & 81,0 & - \\
\hline $\mathrm{Fe}$ & 0,58 & $<0,002$ & 0,45 & 0,34 & 0,65 & 1,00 & 1,41 & 0,86 & 1,51 & 1,23 & 0,3 \\
\hline Mn & 1,34 & $<0,001$ & 0,04 & 0,02 & 0,08 & 0,08 & 0,21 & 0,22 & 0,19 & 0,16 & 0,1 \\
\hline Al & 0,35 & 0,02 & 0,25 & 0,05 & 0,15 & 0,08 & 0,35 & 0,05 & 0,22 & 0,08 & 0,1 \\
\hline $\mathrm{Cu}$ & 0,27 & $<0,002$ & $<0,002$ & $<0,002$ & $<0,002$ & $<0,002$ & 0,01 & $<0,002$ & 0,02 & $<0,002$ & 0,009 \\
\hline $\mathrm{Zn}$ & 0,07 & $<0,003$ & 0,02 & $<0,003$ & 0,07 & 0,02 & 0,08 & $<0,003$ & 0,09 & 0,03 & 0,18 \\
\hline $\mathrm{Cr}$ & $<0,002$ & $<0,002$ & $<0,002$ & $<0,002$ & $<0,002$ & $<0,002$ & $<0,002$ & $<0,002$ & $<0,002$ & $<0,002$ & 0,05 \\
\hline Cd & 0,002 & $<0,002$ & 0,002 & $<0,002$ & 0,002 & $<0,002$ & 0,004 & $<0,002$ & 0,003 & $<0,002$ & 0,001 \\
\hline $\mathbf{P b}$ & $<0,003$ & $<0,003$ & $<0,003$ & $<0,003$ & $<0,003$ & $<0,003$ & $<0,003$ & $<0,003$ & $<0,003$ & $<0,003$ & 0,01 \\
\hline $\mathrm{Hg}$ & $<0,00002$ & $<0,00002$ & $<0,00002$ & $<0,00002$ & $<0,00002$ & 0,53 & $<0,00002$ & 2,14 & $<0,00002$ & 3,46 & 0,0002 \\
\hline
\end{tabular}

entre 3,0 e 54,1 $\mathrm{mg} \mathrm{L}^{-1} \mathrm{O}_{2}$ (média 14,5; $\mathrm{n}=30$ ). Ao mesmo tempo, os valores de DQO estão situados entre 8,0 e $184,0 \mathrm{mg} \mathrm{L}^{-1} \mathrm{O}_{2}$ (média 38,7; $\mathrm{n}=30$ ). A razão $\mathrm{DBO}_{5} / \mathrm{DQO}$ varia entre 0,29 e 0,67 e média 0,43 .

Os valores do potencial hidrogeniônico-pH situaram-se entre 5,3 e 7,5 (média 6,7; n = 30), estando dentro da faixa de variação das águas naturais. A temperatura, por sua vez, variou de 16 a $32{ }^{\circ} \mathrm{C}$ (média 20,5; n $=30$ ), situando-se dentro do intervalo de temperatura regional. A condutividade elétrica variou de 23 a 923 $\mathrm{mS} / \mathrm{cm}$ (média 278; $\mathrm{n}=30$ ). A concentração de oxigênio dissolvido variou de 2 a $11,8 \mathrm{mg} / \mathrm{L}^{-1} \mathrm{O}_{2}$ (média 5,95; $\mathrm{n}=30$ ).

0 teor de ferro nas águas dos arroios estudados variou entre 0,30 e $3,57 \mathrm{mg} \mathrm{L}^{-1}$ (média 1,3; $\mathrm{n}=29$ ), exce- dendo, em vinte e sete das trinta amostras, o limite máximo estabelecido pelo CONAMA $\left(0,3 \mathrm{mg} \mathrm{L}^{-1}\right)$. 0 manganês apresentou concentrações entre 0,01 e 1,34 $\mathrm{mg} \mathrm{L}^{-1}$ (média 0,$2 ; \mathrm{n}=25$ ), estando, em doze amostras, acima do limite do CONAMA para águas doces de Classe $2(0,1$ $\left.\mathrm{mg} \mathrm{L}^{-1}\right)$, correspondente a sete pontos. Em sete amostras, os teores de manganês ficaram situados abaixo do LD $\left(0,005 \mathrm{mg} \mathrm{L}^{-1}\right)$, sendo quatro amostras correspondentes a dois pontos nos períodos de superávit e déficit hídrico.

0 alumínio foi detectado em vinte e nove das trinta amostras em concentrações que variam entre 0,02 e 2,88 $\mathrm{mg} \mathrm{L}^{-1}$ (média 0,$6 ; \mathrm{n}=30$ ). Como o limite máximo proposto pelo CONAMA é $0,1 \mathrm{mg} \mathrm{L}^{-1}$, vinte e quatro das trinta amostras não podem ser enquadradas como Clas- 
Tabela 3. Parâmetros físico-químicos e concentrações de metais ( $\mathrm{mg} \mathrm{L}^{-1}$ ) na água da sub-bacia do Arroio Passo das Pedras. Obs: em negrito, valores acima do limite estabelecido pela resolução CONAMA no 357/ 2005 para águas doce Classe 2. S = período de déficit hídrico (seco); C = período de superávit hídrico (chuvoso).

\begin{tabular}{|c|c|c|c|c|c|c|c|c|c|c|c|}
\hline Parâmetro & PED 1C & PED 1S & PED 2C & PED 2S & PED 3C & PED $3 S$ & PED 4C & PED 4S & PED 5C & PED 5S & CONAMA \\
\hline $\mathrm{pH}$ & 5,8 & 5,9 & 7,0 & 6,5 & 7,5 & 7,1 & 7,4 & 7,2 & 7,2 & 6,9 & - \\
\hline $\mathbf{T}$ & 23 & 19 & 19 & 19 & 21 & 20 & 25 & 22 & 25 & 21 & - \\
\hline $\mathrm{CE}$ & 35 & 23 & 311 & 267 & 923 & 579 & 160 & 587 & 779 & 447 & - \\
\hline OD & 6,9 & 8,3 & 6,8 & 7,8 & 2,2 & 3,3 & 1,3 & 1,8 & 1,8 & 1,8 & - \\
\hline $\mathrm{DBO}_{5}$ & 9,0 & 4,0 & 9,1 & 6,0 & 54,1 & 45,0 & 52,3 & 42,0 & 8,5 & 30,0 & 5 \\
\hline DQO & 27,7 & 8,0 & 28,6 & 12,0 & 184,0 & 96,0 & 176,0 & 85,0 & 26,9 & 72,0 & - \\
\hline $\mathrm{Fe}$ & 0,30 & 0,30 & 1,51 & 0,68 & 2,79 & 1,42 & 3,57 & 1,48 & 1,98 & 2,14 & 0,3 \\
\hline Mn & $<0,001$ & $<0,001$ & 0,10 & 0,05 & 0,45 & 0,38 & 0,50 & 0,38 & 0,45 & 0,31 & 0,1 \\
\hline Al & 0,40 & 0,61 & 0,26 & 0,44 & 0,33 & 0,11 & 0,26 & 0,23 & 0,28 & 0,51 & 0,1 \\
\hline $\mathrm{Cu}$ & $<0,002$ & $<0,002$ & $<0,002$ & $<0,002$ & 0,01 & $<0,002$ & 0,01 & $<0,002$ & $<0,002$ & $<0,002$ & 0,009 \\
\hline $\mathrm{Zn}$ & 0,07 & $<0,003$ & 0,02 & 0,01 & 0,13 & $<0,003$ & 0,13 & $<0,003$ & 0,03 & 0,04 & 0,18 \\
\hline $\mathrm{Cr}$ & $<0,002$ & $<0,002$ & $<0,002$ & $<0,002$ & $<0,002$ & $<0,002$ & $<0,002$ & $<0,002$ & 0,26 & $<0,002$ & 0,05 \\
\hline $\mathrm{Cd}$ & 0,003 & $<0,002$ & 0,005 & $<0,002$ & 0,004 & $<0,002$ & 0,005 & $<0,002$ & 0,050 & $<0,002$ & 0,001 \\
\hline $\mathrm{Pb}$ & $<0,003$ & $<0,003$ & $<0,003$ & $<0,003$ & $<0,003$ & $<0,003$ & $<0,003$ & $<0,003$ & $<0,003$ & $<0,003$ & 0,01 \\
\hline $\mathrm{Hg}$ & $<0,00002$ & $<0,00002$ & $<0,00002$ & $<0,00002$ & $<0,00002$ & $<0,00002$ & $<0,00002$ & $<0,00002$ & $<0,00002$ & $<0,00002$ & 0,0002 \\
\hline
\end{tabular}

se 2 e dezoito delas correspondem a pontos que não apresentaram variação sazonal significativa. Todas as amostras coletadas na sub-bacia do Arroio Cavalhada durante os meses de déficit hídrico estão enquadradas como Classe 2. Ao mesmo tempo, as demais amostras estão acima do limite em ambas as estações. A única exceção é a amostra LAM1, coletada ao fim do período de superávit hídrico, na qual o alumínio foi encontrado em concentração inferior ao $\operatorname{LD}\left(0,007 \mathrm{mg} \mathrm{L}^{-1}\right)$.

0 zinco foi registrado em concentrações inferiores ao $\operatorname{LD}\left(0,003 \mathrm{mg} \mathrm{L}^{-1}\right)$ em onze amostras referentes ao período de déficit hídrico. Nos demais casos, as concentrações variaram entre 0,02 e $0,13 \mathrm{mg} \mathrm{L}^{-1}$ (média 0,04; $\mathrm{n}=19$ ), valor inferior ao limite do CONAMA para águas doces da Classe $2\left(0,18 \mathrm{mg} \mathrm{L}^{-1}\right)$. 0 conteúdo de cobre situou-se abaixo do $\operatorname{LD}\left(0,01 \mathrm{mg} \mathrm{L}^{-1}\right)$ em vinte e quatro amostras, enquanto, nas seis restantes, os valores variaram entre 0,01 e $0,27 \mathrm{mg} \mathrm{L}^{-1}$ (média 0,03; $\mathrm{n}=6$ ), superiores ao limite estabelecido pela resolução do CONAMA para águas de Classe $2\left(0,009 \mathrm{mg} \mathrm{L}^{-1}\right)$.

As concentrações de cromo situaram-se abaixo do LD $\left(0,002 \mathrm{mg} \mathrm{L}^{-1}\right)$, à exceção de uma amostra do Arroio Lami (LAM5), no período de superávit hídrico $(0,26$ $\mathrm{mg} \mathrm{L}^{-1}$ ), cujo valor foi bem superior ao limite da legislação ambiental para águas da Classe $2\left(0,05 \mathrm{mg} \mathrm{L}^{-1}\right)$. 0 cádmio apresentou teores acima do $\operatorname{LD}(0,002 \mathrm{mg}$ $\mathrm{L}^{-1}$ ) somente no período de superávit hídrico, em todos cursos d'água estudados, variando entre 0,002 e 0,050 (média 0,$006 ; n=11$ ), valores superiores ao limite de $0,001 \mathrm{mg} \mathrm{L}^{-1}$ do CONAMA para águas doces de Classe 2 . As demais amostras, incluindo a totalidade das amostras coletadas no período de déficit hídrico, bem como os pontos situados entre LAM2 e LAM5 ficaram abaixo do LD.

Uma amostra (LAM1, período de superávit hídrico) apresentou relativamente elevada concentração de chumbo $\left(0,05 \mathrm{mg} \mathrm{L}^{-1}\right)$, cinco vezes superior ao li- mite estabelecido pelo CONAMA para águas de Classe $2\left(0,01 \mathrm{mg} \mathrm{L}^{-1}\right)$. As demais vinte e nove amostras não apresentaram teores detectáveis $\left(0,003 \mathrm{mg} \mathrm{L}^{-1}\right)$ através do método analítico utilizado.

O mercúrio esteve presente acima do $\operatorname{LD}(0,00002$ $\mathrm{mg} \mathrm{L}^{-1}$ ) em três das trinta amostras analisadas, variando entre 0,002 e $0,004 \mathrm{mg} \mathrm{L}^{-1}$, valores muito superiores ao limite do CONAMA $\left(0,0002 \mathrm{mg} \mathrm{L}^{-1}\right)$ para águas de Classe 2. As três amostras contaminadas provem dos pontos a jusante da sub-bacia do Arroio Cavalhada.

\subsection{Sedimentos de corrente}

As concentrações de seis metais $(\mathrm{Cu}, \mathrm{Zn}, \mathrm{Cr}, \mathrm{Cd}, \mathrm{Pb}$ e Hg) e de matéria orgânica nos sedimentos de corrente dos Arroios Lami, Cavalhada e Passo das Pedras são apresentadas nas Tabelas 4, 5 e 6. Para a caracterização dos sedimentos de corrente, foram utilizados os valores de referência da resolução 344/2004 do CONAMA, considerando-se águas doces de Nível 1.

0 conteúdo de matéria orgânica variou entre 0,21 e 14,8 $\mathrm{mg} \mathrm{kg}^{-1}$ (média 7,6; $\mathrm{n}=30$ ), sendo sazonalmente distribuído entre 12,0 e $14,8 \mathrm{mg} \mathrm{kg}^{-1}$ no período de superávit hídrico e entre 0,20 e $6,8 \mathrm{mg} \mathrm{kg}^{-1}$ no período de déficit hídrico.

As concentrações de zinco ficaram compreendidas entre 0,72 e 100,3 $\mathrm{mg} \mathrm{kg}^{-1}$ (média 15,5; $\mathrm{n}=28$ ), enquanto nas duas restantes situaram-se abaixo do LD $\left(0,003 \mathrm{mg} \mathrm{kg}^{-1}\right)$, correspondendo a pontos amostrados durante o período de déficit hídrico nos Arroios Lami e Passo das Pedras.

O cobre, cromo e chumbo apresentaram distribuição e comportamento semelhante nos sedimentos de corrente. Em quinze das amostras analisadas, correspondentes ao período de superávit hídrico, as concentrações variaram entre 0,12 e 7,93 $\mathrm{mg} \mathrm{kg}^{-1}$ (média 0,74; $\mathrm{n}=15$ ) para o cobre, 0,10 e 5,29 $\mathrm{mg} \mathrm{kg}^{-1}$ (média 0,96; 
Tabela 4. Concentração de metais e matéria orgânica (mg kg-1) em sedimentos de corrente da sub-bacia do Arroio Lami. Obs: em negrito, valores enquadrados nos limites estabelecidos pela resolução CONAMA no 344/ 2004 para sedimentos Nível 1. S = período de déficit hídrico (seco); C = período de superávit hídrico (chuvoso).

\begin{tabular}{l|cccccccc|c|c|c|c|c}
\hline Parâmetro & LAM 1C & LAM 1S & LAM 2C & LAM 2S & LAM 3C & LAM 3S & LAM 4C & LAM 4S & LAM 5C & LAM 5S & CONAMA \\
\hline MO & 14,0 & 1,1 & 12,8 & 0,43 & 13,9 & 0,21 & 13,1 & 0,25 & 14,8 & 5,0 & - \\
Zn & 2,20 & 6,08 & 3,84 & 0,72 & 4,66 & $<0,003$ & 2,16 & 4,19 & 6,18 & 34,2 & 123 \\
Cu & 0,43 & $<0,002$ & 0,38 & $<0,002$ & 0,50 & $<0,002$ & 0,12 & $<0,002$ & 0,54 & 1,64 & 35,7 \\
Cr & 1,0 & $<0,002$ & 0,17 & $<0,002$ & 0,12 & $<0,002$ & 0,10 & $<0,002$ & 0,36 & $<0,002$ & 37,3 \\
Cd & 0,03 & $<0,002$ & 0,06 & $<0,002$ & 0,08 & $<0,002$ & 0,07 & $<0,002$ & 0,11 & $<0,002$ & 0,6 \\
Pb & 0,07 & $<0,003$ & 2,11 & $<0,003$ & 1,83 & $<0,003$ & 0,09 & $<0,003$ & 1,63 & $<0,003$ & 35 \\
Hg & $<0,0002$ & 0,003 & 0,05 & 0,003 & 0,06 & 0,019 & $<0,0002$ & 0,006 & $<0,0002$ & 0,024 & 0,17 \\
\hline
\end{tabular}

Tabela 5. Concentração de metais e matéria orgânica $\left(\mathrm{mg} \mathrm{kg}^{-1}\right)$ em sedimentos de corrente da sub-bacia do Arroio Cavalhada. Obs: em negrito, valor acima do limite estabelecido pela resolução CONAMA no 344/ 2004 para sedimentos Nível 1 . $S=$ período de déficit hídrico (seco); C = período de superávit hídrico (chuvoso).

\begin{tabular}{l|ccc|c|c|c|c|c|c|c|c|c}
\hline Parâmetro & CAV 1C & CAV 1S & CAV 2C & CAV 2S & CAV 3C & CAV 3S & CAV 4C & CAV 4S & CAV 5C & CAV 5S & CONAMA \\
\hline MO & 13,8 & 0,43 & 14,2 & 0,46 & 13,1 & 0,30 & 13,0 & 0,41 & 12,0 & 1,8 & - \\
Zn & 3,10 & 43,5 & 7,77 & 3,44 & 5,51 & 22,9 & 12,4 & 13,8 & 31,0 & 17,2 & 123 \\
Cu & 0,33 & $<0,002$ & 1,11 & $<0,002$ & 0,76 & $<0,002$ & 3,0 & $<0,002$ & 2,39 & $<0,002$ & 35,7 \\
Cr & 0,11 & $<0,002$ & 0,40 & $<0,002$ & 0,27 & $<0,002$ & 0,53 & $<0,002$ & 0,26 & $<0,002$ & 37,3 \\
Cd & 0,04 & $<0,002$ & 0,03 & $<0,002$ & 0,03 & $<0,002$ & 0,05 & $<0,002$ & 0,17 & $<0,002$ & 0,6 \\
Pb & 0,08 & $<0,003$ & 0,07 & $<0,003$ & 4,18 & $<0,003$ & 1,24 & $<0,003$ & 0,21 & $<0,003$ & 35 \\
Hg & 0,05 & $<0,0002$ & 0,13 & $<0,0002$ & $<0,0002$ & $<0,0002$ & $\mathbf{0 , 2 1}$ & $<0,0002$ & 0,07 & $<0,0002$ & 0,17 \\
\hline
\end{tabular}

Tabela 6. Concentração de metais e matéria orgânica $\left(\mathrm{mg} \mathrm{kg}^{-1}\right)$ em sedimentos de corrente da sub-bacia do Arroio Passo das Pedras. Obs: em negrito, valores enquadrados nos limites estabelecidos pela resolução CONAMA no 344/ 2004 para sedimentos Nível 1 . S = período de déficit hídrico (seco); C = período de superávit hídrico (chuvoso).

\begin{tabular}{l|c|c|c|c|c|c|c|c|c|c|c}
\hline Parâmetro & PED 1C & PED 1S & PED 2C & PED 2S & PED 3C & PED 3S & PED 4C & PED 4S & PED 5C & PED 5S & CONAMA \\
\hline MO & 12,2 & 4,7 & 12,9 & 1,8 & 13,7 & 1,9 & 12,6 & 0,72 & 14,3 & 6,8 \\
Zn & 2,51 & 15,7 & 6,74 & $<0,003$ & 11,0 & 20,9 & 15,7 & 0,93 & 20,4 & 100,3 & 123 \\
Cu & 0,65 & 12,9 & 0,56 & $<0,002$ & 2,25 & $<0,002$ & 1,37 & $<0,002$ & 7,93 & 19,9 & 35,7 \\
Cr & 1,94 & 23,0 & 1,12 & $<0,002$ & 1,31 & $<0,002$ & 1,40 & $<0,002$ & 5,29 & 4,36 & 37,3 \\
Cd & 0,14 & $<0,002$ & 0,15 & $<0,002$ & 0,24 & $<0,002$ & 0,11 & $<0,002$ & 0,30 & $<0,002$ & 0,6 \\
Pb & 5,32 & 13,6 & 3,65 & $<0,003$ & 0,31 & $<0,003$ & 0,34 & $<0,003$ & 9,23 & 15,5 & 35 \\
Hg & 0,08 & 0,077 & 0,10 & $<0,0002$ & 0,07 & 0,011 & 0,04 & 0,012 & 0,09 & $<0,0002$ & 0,17 \\
\hline
\end{tabular}

$\mathrm{n}=15$ ) para o cromo e 0,07 e 9,23 $\mathrm{mg} \mathrm{kg}^{-1}$ (média 1,52; $\mathrm{n}=15$ ) para o chumbo. Durante a campanha do período de déficit hídrico, os três elementos foram registrados em teores acima dos LDs ( $\mathrm{Cu}$ e $\mathrm{Cr}=0,002 \mathrm{mg} \mathrm{kg}^{-1} ; \mathrm{Pb}$ $=0,003 \mathrm{mg} \mathrm{kg}^{-1}$ ) em apenas duas amostras, que correspondem aos pontos mais à montante e mais à jusante da sub-bacia do Arroio Passo das Pedras. Nestes pontos, o cobre variou entre 12,9 a $19,9 \mathrm{mg} \mathrm{kg}^{-1}$, o cromo entre 4,36 à $23,0 \mathrm{mg} \mathrm{kg}^{-1} \mathrm{e}$ o chumbo entre 13,6 à 15,5 $\mathrm{mg} \mathrm{kg}^{-1}$. O cobre ainda esteve presente no ponto mais à jusante do Arroio Lami (1,64 $\left.\mathrm{mg} \mathrm{kg}^{-1}\right)$, enquanto doze amostras restantes apresentaram concentrações inferiores aos limites de detecção para os métodos analíticos utilizados $\left(0,003 \mathrm{mg} \mathrm{kg}^{-1}\right.$ - chumbo, 0,002 $\mathrm{mg} \mathrm{kg}^{-1}$ - cromo e cobre).

0 cádmio, no período de superávit hídrico, variou entre 0,03 e 0,30 $\mathrm{mg} \mathrm{kg}^{-1}$ (média $0,11 \mathrm{n}=15$ ), enquanto nas quinze amostras correspondentes à estação de déficit hídrico as concentrações mostraram-se inferio- res ao LD do método analítico $\left(0,002 \mathrm{mg} \mathrm{kg}^{-1}\right)$. Os teores de mercúrio mostraram-se entre 0,003 e 0,130 mg $\mathrm{kg}^{-1}$ (média 0,059; $\mathrm{n}=18$ ). Uma única amostra coletada no período de superávit hídrico (ponto CAV4) alcançou $0,21 \mathrm{mg} \mathrm{kg}^{-1}$, teor superior ao limite da Resolução $344 / 2004$ do CONAMA $\left(0,17 \mathrm{mg} \mathrm{kg}^{-1}\right)$. As restantes onze amostras não apresentaram valores detectáveis ( $\mathrm{LD}=0,0002 \mathrm{mg} \mathrm{kg}^{-1}$ ). Em cinco pontos, o mercúrio foi detectado nas duas estações.

\section{Discussão dos resultados}

A análise dos resultados das análises físico-químicas mostrou que há uma variação expressiva da concentração de certos parâmetros. No caso das amostras provenientes da sub-bacia do Arroio Passo das Pedras, as medidas de $\mathrm{DBO}_{5}$, DQO e Cd atingiram valores bastante elevados, inclusive junto à nascente, onde se registrou circulação de moradores que habitam as áreas 
de risco do entorno. No início do curso médio deste arroio, os níveis de poluição são atenuados naturalmente por uma extensa área verde, devido a inexistência de novos pontos de lançamentos de dejetos e, provavelmente, a degradação química dos poluentes. No trecho final do curso médio e no início do curso inferior, a densa urbanização afeta diretamente a qualidade da água, o que pode ser verificado pelo crescimento dos valores dos principais parâmetros ambientais. A situação é atenuada no trecho final do arroio, em virtude da descarga de água advinda de uma estação de tratamento de esgoto. Já os resultados analíticos obtidos na sub-bacia do Arroio Cavalhada, em particular as concentrações de $\mathrm{DBO}_{5}$, Cu e Cd demonstraram forte influência de dejetos domésticos junto à foz. Na sub-bacia do Arroio Lami, o volume de esgotos lançados in natura é, em toda a extensão do curso d'água, inferior aos demais, como os números ressaltaram no trecho inferior (DBO $_{5}$ média de $8 \mathrm{mg} \mathrm{L}^{-1} \mathrm{O}_{2}$, contra $15 \mathrm{mg} \mathrm{L}^{-1} \mathrm{O}_{2}$ em CAV e $33 \mathrm{mg} \mathrm{L}^{-1} \mathrm{O}_{2}$ em PED), abrangido por uma reserva biológica municipal.

No que se refere às diferenças de qualidade ambiental entre os dois compartimentos amostrados (ver

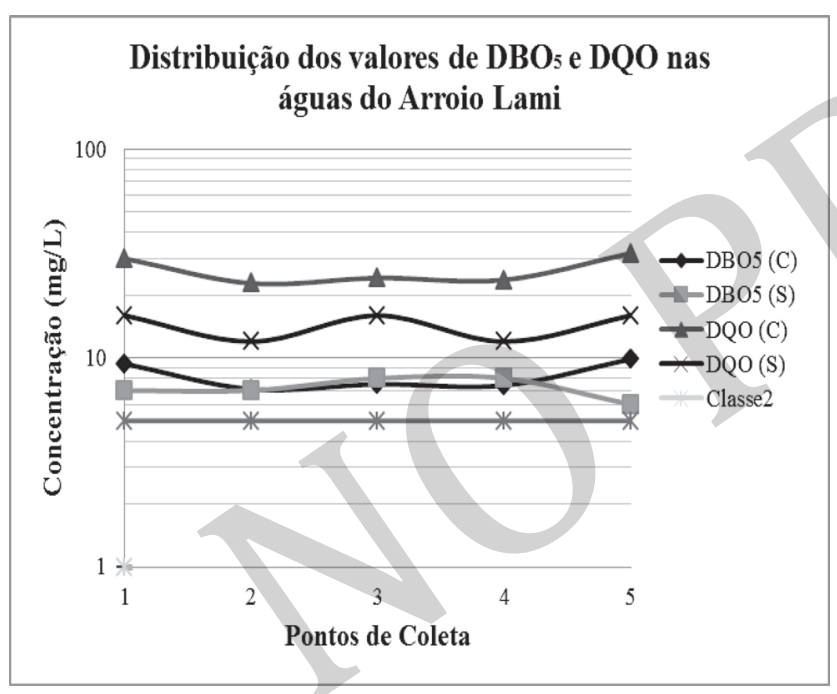

Figura 4. Distribuição dos teores de $\mathrm{DBO}_{5}$ e DQO nas águas da sub-bacia do Arroio Lami.

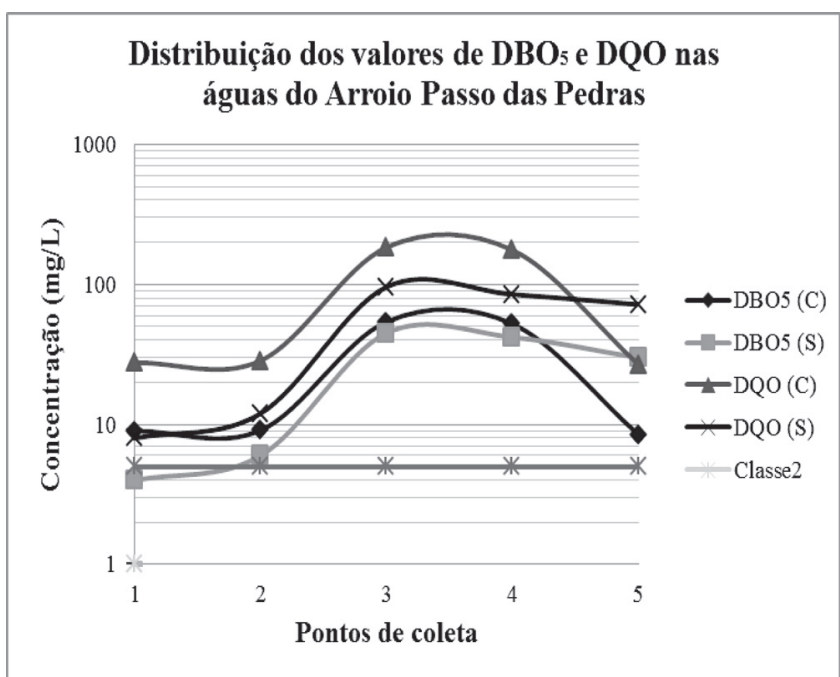

Figura 5. Distribuição dos teores de $\mathrm{DBO}_{5}$ e DQO nas águas da sub-bacia do Arroio Cavalhada. figuras 4 a 9), verificou-se que as águas superficiais das três sub-bacias registram um maior número de casos que ultrapassam os valores de referência da legislação ambiental, se comparados com os sedimentos de corrente. Esta situação decorre do material particulado ser essencialmente arenoso, com pouca incidência de sedimentos finos, cuja capacidade de adsorção é maior. 0 mercúrio detectado em sedimentos de corrente alcançou valor superior à legislação ambiental somente em um ponto situado no curso médio do Arroio Cavalhada, à montante de uma indústria de abate de aves, não tendo sido, porém, localizadas fontes potenciais desse elemento na região. No caso das águas superficiais, deve ser destacado que os níveis elevados de $\mathrm{DBO}_{5}$ servem de indício da presença de esgotos domésticos em quantidades que extrapolam a capacidade de autodepuração do meio. Ficou evidente, também, que metais-traço estão presentes em teores mais elevados nas áreas de maior adensamento urbano das sub-bacias dos Arroios Cavalhada e Passo das Pedras. No caso do cádmio, seus teores se devem, provavelmente, à degradação de baterias, utensílios domésticos e peças automotivas.

Após a análise dos dados obtidos, é possível afir-

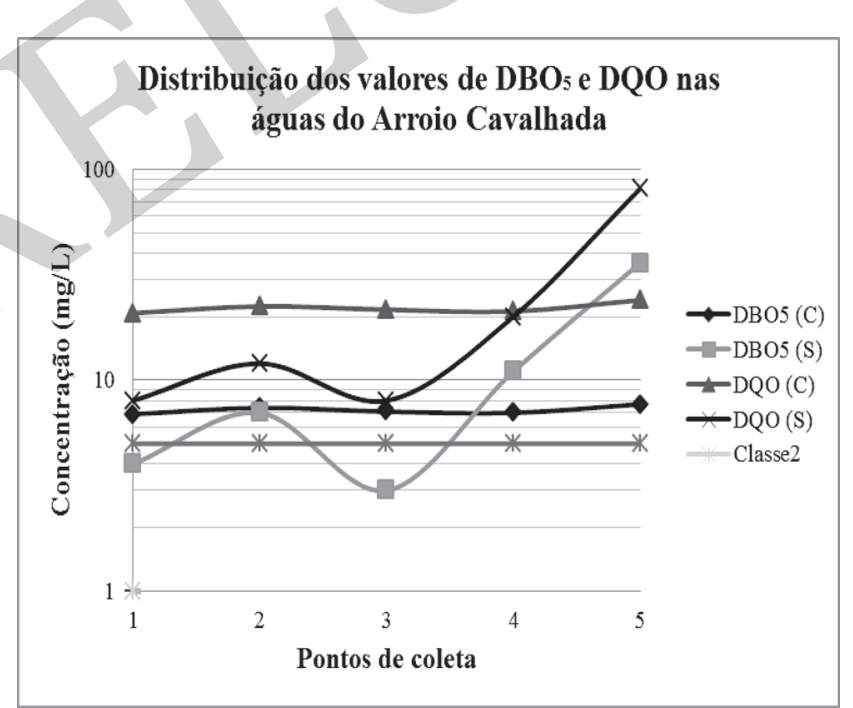

Figura 6. Distribuição dos teores de $\mathrm{DBO}_{5}$ e DQO nas águas da sub-bacia do Arroio Passo das Pedras.

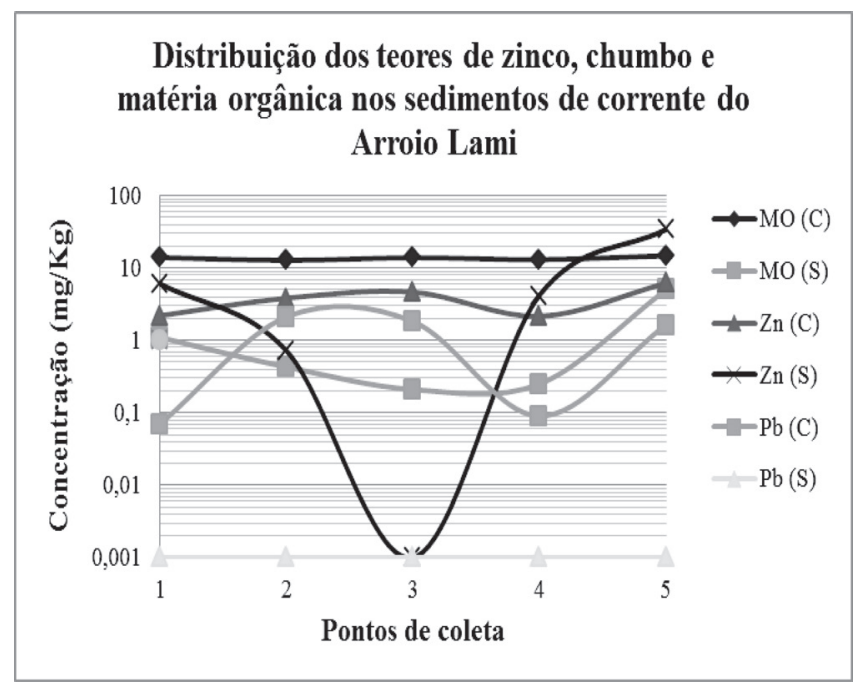

Figura 7. Distribuição dos teores de zinco, chumbo e matéria orgânica nos sedimentos de corrente do Arroio Lami. 


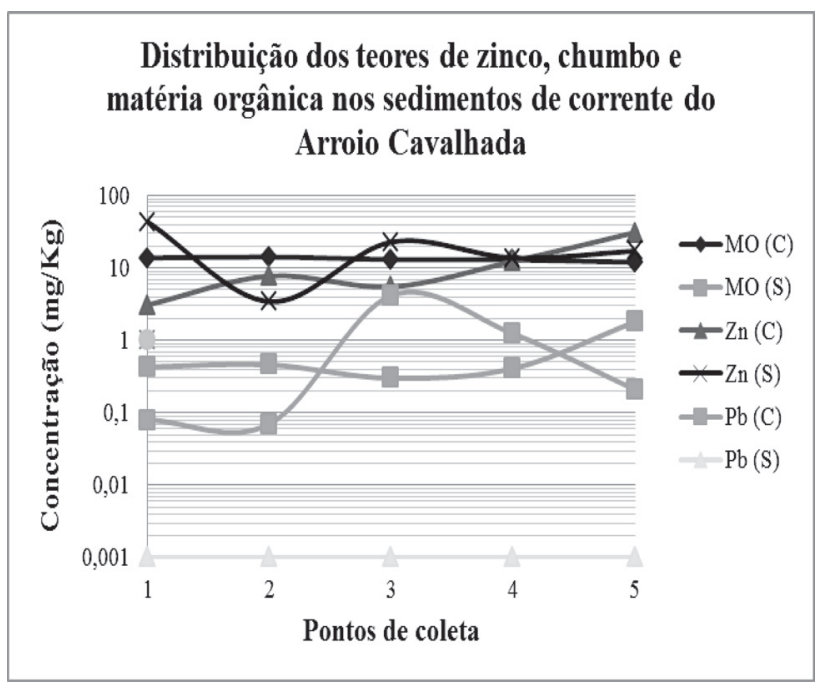

Figura 8. Distribuição dos teores de zinco, chumbo e matéria orgânica nos sedimentos de corrente do Arroio Cavalhada.

mar que a qualidade ambiental está sendo fortemente influenciada pela variação do grau de urbanização verificado entre a nascente e a foz das sub-bacias. A sub-bacia do Arroio Passo das Pedras possui o grau de urbanização mais elevado dentre as áreas estudadas e, consequentemente, apresentou os maiores níveis de degradação ambiental. Na sub-bacia do Arroio Cavalhada, o grau de urbanização é intermediário, resultado da baixa densidade populacional no curso superior. A sub-bacia do Arroio Lami, por sua vez, apresenta o menor grau de urbanização, devido ao afastamento dos eixos de expansão da cidade de Porto Alegre. Como consequência, exibiu as melhores condições de qualidade ambiental dentre as áreas estudadas.

\section{Conclusões}

O diagnóstico hidrogeoquímico das três sub-bacias analisadas no Município de Porto Alegre demonstrou, claramente, os diferentes graus de impacto da urbanização e do uso e ocupação do território na composição físico-química de águas e sedimentos de corrente. Desta forma, pode-se afirmar que os resultados analíticos obtidos corroboraram o zoneamento urbano-ambiental existente (Porto Alegre, 1999), elaborado, essencialmente, a partir da análise das demografias habitacionais e populacionais, da organização territorial e da vegetação.

A sub-bacia do Arroio Lami representou a drenagem menos afetada pela urbanização, face à relativamente baixa densidade populacional e ausência de atividade industrial. Por sua vez, a sub-bacia do Arroio Passo das Pedras revelou uma situação diametralmente oposta, decorrente do alto grau de urbanização e da presença de seis unidades industriais de porte e potencial poluidor elevados. A sub-bacia do Arroio Cavalhada, caracterizada por padrão de ocupação rarefeito no trecho à montante e presença de cinco unidades industriais, representa um cenário de transição entre os dois contextos anteriormente referidos.

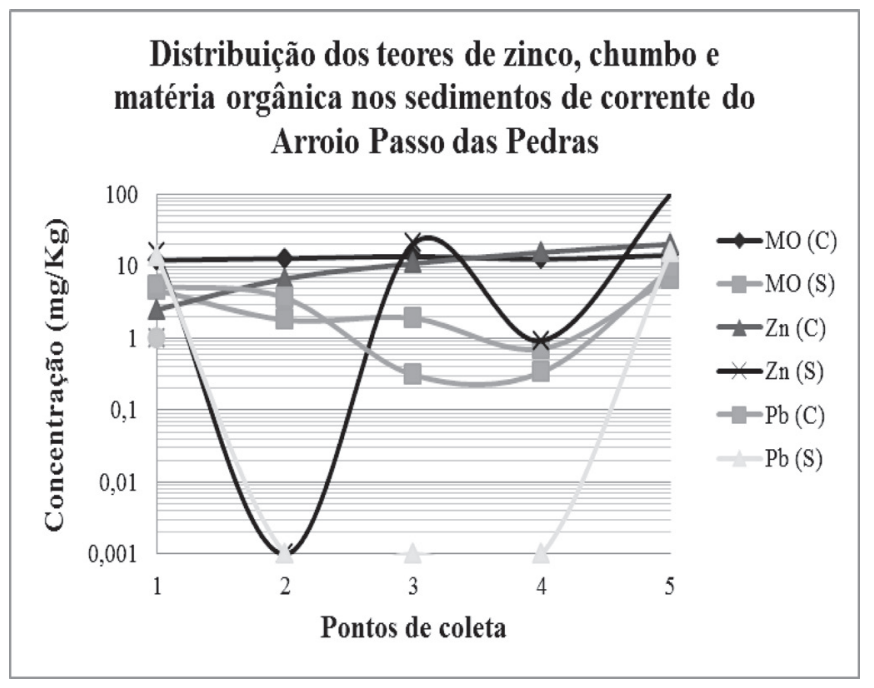

Figura 9. Distribuição dos teores de zinco, chumbo e matéria orgânica nos sedimentos de corrente do Arroio Passo das Pedras.

A variação nos teores dos principais parâmetros ao longo das campanhas de amostragem, registrada nos laudos de análise físico-química do conjunto de amostras, indicou um aumento na carga de dejetos no período de maior pluviosidade. Este fato é explicado pelo registro de baixos níveis de precipitação pluviométrica nos dias que antecederam a campanha de amostragem e ao tempo de residência da água relativamente baixo nas sub-bacias, propriedade esta relacionada, principalmente, às dimensões reduzidas das três áreas de estudo.

Para finalizar, os níveis de degradação registrados nos três arroios evidenciaram a necessidade de ampliação da rede de coleta e tratamento de esgotos, como medida para mitigar a carga de poluentes que atingem o Lago Guaíba. Considerando que este manancial é utilizado como fonte principal para o abastecimento do próprio município de Porto Alegre, ações que reduzam a degradação da sua qualidade servirão, também, para diminuir os custos de seu tratamento.

Agradecimentos - Os autores agradecem ao Conselho Nacional de Desenvolvimento Científico e Tecnológico - CNPq por haver atribuído bolsa de doutorado a um dos autores (R.M.). Este trabalho é parte constituinte de tese de doutoramento vinculada ao IG/UFRGS.

\section{Referências}

APHA. American Public Health Association. 1995. Standard methods for the examination of water and wastewater. 19ed. Washington, APHA, 1134p.

Bertalanffy, L. 1973. Teoria Geral dos Sistemas. Petrópolis, Vozes, 351p.

Bertrand, G. 1971. Paisagem e geografia física global: esboço metodológico. Caderno de Ciências da Terra (IGEO/USP), 13: $1-27$.

Christofoletti, A. 1999. Modelagem de sistemas ambientais. São Paulo, Edgard Blücher, 236p.

CETESB. Companhia de Tecnologia de Saneamento Ambiental. 1987. Guia de coleta e preservação de amostras de água. São Paulo, CETESB, 155p. 
CONAMA. Conselho Nacional do Meio Ambiente. Resolução 344/2004. Disponível em:<http://www.mma.gov.br/ port/conama/legiabre.cfm?codlegi $=445>$. Acessado em: 07 mai. 2011.

CONAMA. Conselho Nacional do Meio Ambiente. Resolução 357/2005. Disponível em:<http://www.mma.gov.br/ port/conama/legiabre.cfm?codlegi=459>. Acessado em: 07 mai. 2011.

Crepani, E., Medeiros, J.S., Azevedo, L.G., Hernandez Filho, P., Florenzano, T.G.\& Duarte, V. 1996. Curso de sensoriamento remoto aplicado ao zoneamento econômico-ecológico. São José dos Campos, INPE.

Fragoso-Cesar, A.R.S., Figueiredo, M.C.H., Soliani Jr., E.\& Faccini, U.F. 1986. O Batólito de Pelotas (Proterozóico Superior/ Eo-Paleozóico) no Escudo do Rio Grande do Sul. In: CONGRESSO BRASILEIRO DE GEOLOGIA, 34, Goiânia, 1986. Anais..., Goiânia, SBG, v. 3, p. 1322-1343.

Freitas, M.A. 1998. Avaliação do potencial hidrogeológico de terrenos cristalinos através de técnicas de geoprocessamento. Porto Alegre, 127p. Dissertação de Mestrado, Programa de Pós-graduação em Geociências, Instituto de Geociências, Universidade Federal do Rio Grande do Sul.

Guerra, T., Spanemberg, G.S., Pedroso, C., Zancan, L.C., Hasenack, H. \& Machado, N.A.F. 1998. Avaliação ambiental da microbacia do Arroio Cavalhada, Porto Alegre, RS, Brasil. In: SIMPÓSIO INTERNACIONAL DE QUALIDADE AMBIENTAL, 2 - Gerenciamento de resíduos e certificação ambiental, 1998, Porto Alegre. Anais..., Porto Alegre, p. 344-358.

IBGE. Instituto Brasileiro de Geografia e Estatística. 1986. Folha SH.22 Projeto RADAMBRASIL - Porto Alegre e parte das folhas SH.21 Uruguaiana e SI.22 Lagoa Mirim: geologia, geomorfologia, pedologia, vegetação, uso potencial da terra. In: Levantamento de Recursos Naturais, 33. Rio de Janeiro, IBGE, 791p.

IBGE. Instituto Brasileiro de Geografia e Estatística. 2010. Banco de dados \Cidades@\Porto_Alegre. Disponível em:<http://www.ibge.gov.br/cidadesat/xtras/perfil. php? codmun=431490\&r=2>. Acessado em: 07mai. 2011.

Lange, O. \& Guerra, T. 2002. Análise ambiental da sub-bacia do Arroio Itapuã. Caderno para educação ambiental
(UFRGS), 1:1-104.

Menegat, R., Porto, M.L., Carraro, C.C. \& Fernandes, L.A.D. 1998. Atlas Ambiental de Porto Alegre. Porto Alegre, Editora da UFRGS, 228p.

Peel, M.C., Finlayson, B.L. \& McMahon, T.A. 2007. Updated world map of the Köppen-Geiger climate classification. Hydrology and Earth Systems Sciences, 11:1633-1644. Disponível em:<http://www.hydrol earth syst sci. net/11/1633/2007/hess-11-1633-2007.pdf > . Acessado em: 15 mai. 2013.

Porto Alegre. 2012. Rede Metroclima: Médias históricas do nível do Lago Guaíba e da Precipitação Pluviométrica de Porto Alegre. Disponível em: <http:// www2 .portoalegre.rs.gov.br/metroclima/default.php? p secao=16>. Acessado em: 23 jan. 2012.

Porto Alegre. 1999. Lei Complementar 434 (Plano Diretor de Desenvolvimento Urbano Ambiental - PDDUA). Disponível em:<http://www.portoalegre.rs.gov.br/planeja/ pddua.htm>. Acessado em: 07 mai. 2011.

Ross, J.L.S. 1990. Geomorfologia: ambiente e planejamento. São Paulo, Contexto, 85p.

Sentelhas, P.C., Pereira, A.R., Marin, F.R., Angelocci, L.R., Alfonsi, R.R., Caramori, P.H. \& Swart, S. 1999. Balanços Hídricos Climatológicos do Brasil - 500 balanços hídricos de localidades brasileiras. ESALQ, 1 CD-ROM. Disponívelem:<http://www.bdclima.cnpm.embrapa.br/ resultados/balanco.php?UF $=\& C O D=225>$. Acessado em: 07 mai. 2011.

Sotchava, V.B. 1977. O estudo do geossistema. Métodos em Questão, 16:1-51.

Tricart, J. 1977. Ecodinâmica. Rio de Janeiro, IBGE/Supren, 97p.

USEPA. U.S.Environmental Protection Agency. 1979. Methods for chemical analysis of water and wastes (Publ. number 800R71003). Disponível em: <http://nepis.epa.gov/ EPA/html/Pubs/pubtitleOW.html> acessada em 07 mai. 2011.

\section{Manuscrito 476}

Editores: Tânia M. Strohaecker e César L. Shultz. 